\title{
Embodied Knowledge, Tool, and Sketch: Intuitive Production of Knowledge in Architectural Design
}

Nandini Oehlmann

Editorial Summay: Entitled »Embodied Knowledge, Tool, and Sketch«, Nandini Oehlmann's contribution directs the focus to the »intuitive production of knowledge in architectural design", also the subtitle of the text, and aims to trace the tacit, pre-reflective knowledge that plays a guiding role in the design process. As she defines design as having "an idea in mind as a vague notion«, her investigation is driven by the search for a profound understanding of the knowledge transfer of cognitive and manual knowing. She places an emphasis on the evolution of knowledge in the design process, from indistinct premonition to a specific concretization of the design. Tacit knowledge forms the core of this research, aiming to decipher this preconscious experience-based manual or bodily knowledge. [Katharina Voigt]

Keywords: Intuition; Design Process; Manual Knowledge; Tacit Knowledge; Language; Embodiment.

\section{Introduction - On Design Processes}

This research aims to investigate a topic that many designers, architects, and students experience in their everyday work: The process of how an idea, an intention or a design come into being. Designing entails having an initial idea in mind as a vague notion. This idea is then gradually formulated using the hand as an interface. In this setting, the hand has an autonomous function; it reexamines the previous idea and formulates it more specifically. At the same time, it can produce almost independently without cognitive intervention. This research is centered on examining the interface between cognitive and manual or physical knowledge when designing, with a specific focus on the notion of knowledge transfer. 
The thesis of the present research project asserts that there is a form of knowledge preceding cognitive knowledge; a knowledge before knowledge. It is manifested in the body and is therefore called manual or embodied knowledge. The present research investigates this form of knowledge as a special type of implicit knowledge, described by Michael Polanyi as »tacit knowing« (Polanyi 1966).

On one hand, this implies a knowledge of experience that can be used unconsciously. In terms of the design process, this is the knowledge of the pencil stroke made 1000 times, knowledge known inside and out. It is the manual knowledge described by Richard Sennett in his book The Craftsman (cf. Sennett 2008), and how many musicians, for example, experience their practice. On the other hand, it is a prior knowledge, an intuition that guides us when, for example, a line of thought is present as a premonition, but has not yet been specified. ${ }^{1}$ Here, the sketch plays a crucial role as an approximation to an ideal state that has not yet been formulated; it is an essential tool in the cycle of making - acquiring - understanding.

The following article discusses aspects of several theories and thinkers that deal with the relation between body, language, and knowledge that can enrich and expand our knowledge of design processes.

\section{Research Project: Design Process vs. Language Making}

I will approach the aforementioned thesis by examining the relationship between language and knowledge. The discipline of cognitive linguistics precisely examines non-verbal and pre-linguistic thought. Moreover in language, this relationship between implicit and explicit knowledge and intuition and unconscious adaptations in everyday life is applied in a similar manner. Thus, I aim to transfer phenomena of language, how a thought takes shape as a word, to the process of architectural design - how an idea turns into form by means of the body.

Tacit knowing, as well as implicit knowledge, cannot be clearly put into words. It is less related to cognitive structures and more about mental processes; »We can know more than we can tell« (Polanyi 1966: 4). The key

1 Heinrich von Kleist described this phenomenon in his text Über die allmähliche Verfertigung der Cedanken beim Reden (On the Cradual Completion of Thoughts During Speech) from 1805. In the process of speaking, thoughts reveal themselves that would not have been revealed by thinking alone. 
research question therefore inquires: Does the hand know more than we can draw? Is there an embodied pre-knowledge that we can learn to retrieve? How can we make use of this implicit knowledge when we want to transfer knowledge?

The human use of language combines the direct interplay of cognitive knowledge and intuition. We use complex grammatical rules when speaking and writing, yet we can also intuitively form correct sentences without cognitively retrieving the corresponding rules. "Most of our knowledge of language is unconscious. However, this latent knowledge enables us to act as a recognized member of the language community« (Lutzeier 1985: 56. Translation: Nandini Oehlmann).

This notion additionally relates to the implicit acquisition of the mother tongue. Similarly, when designing, we can develop a "feeling« for joining individual parts into a whole. One could consider the practice of proprioceptive, embodied and lived experience as a pre-reflected knowledge: "Embodied organism-environment interactions [...] constitute our understanding of the world « (Lakeoff / Johnson 2002: 249). The experience gained is acquired casually in everyday life and remains available when designing space and construction. Vice versa, a rule can also be internalized by repetition until it is applied.

The verbalization of content occurs on different parallel process levels. At the same time, information is conceptualized, lexicalized, and a linear syntactic structure is generated and articulated in a motorized manner (Schwarz 2008: 210). Our statements are also generated incrementally. Conceptually, we do not completely plan our statements before we verbalize them. It is only in the process of articulation that utterances are conceptually completed (ibid.). »The subject applies these formal rules according to the situation and accurately reproduces patterns and contents of thought without explicitly and reflectively knowing them « (Seiler 2012: 126. Translation: Nandini Oehlmann).

In this context, the sketch - as a spontaneous visualization of a thought plays an important role. Thus, the sketch exists as an interface between the incremental materialization and the formulation of knowledge in the world. The generation of knowledge by sketching is to be understood as a "tool situation«, because what is sketched eludes clear description and thus prevents a generic representation of the intended statement. The manner in which knowledge manifests itself in the world is always technology-based, 
depending on the tool selected. The sketch occupies a special position here; it manifests the characteristic of something still evolving.

The present work is particularly interested in the phenomenon of language due to its implicit acquisition and unconscious use, as well as the substantial amount of existing research in the field of cognitive science. Other than for the »linguistic turn« this is not about semiotic and semantic questions.

\section{Congruence of Language and Thinking}

Our use of language combines a fusion of cognitive knowledge and intuition. We subconsciously use complex grammar, formulate correct sentences, and reproduce content that has not yet been completed. The implicit acquisition of linguistic knowledge indicates that we can use this knowledge intuitively.

»On the one hand it is clear that every sentence in our language sis in order as it is . That is to say, we are not striving after an ideal, as if our ordinary vague sentences had not yet got a quite unexceptionable sense, and a perfect language awaited construction by us. - On the other hand it seems clear that where there is sense there must be perfect order. - So there must be perfect order even in the vaguest sentence.« (Wittgenstein 2009: 26).

In our use of everyday language, we constantly operate with imagined fuzziness and its linguistic description. The intended content is approached in gradual approximation during an ongoing process of conversation. Both communication partners trust that the other person will understand what they mean by an utterance (Bergmann 2005: 128). This elliptical peculiarity of language can be observed analogously in the sketch approach in designing, where images or spaces that have not yet been fully formulated are further conceptualized and developed in manual work.

Some theorists regard this intertwining of the structures of language on the one hand and thinking on the other hand as a process that, due to the close interrelation, cannot take place independently of one another.

Among those scholars is the cognitive psychologist Dietrich Dörner. He postulated that by creating a system that could understand language, one would also create a system that could think (Dörner 1998:41). Regardless of the fact that language also has a social function, it first creates an event pattern, a kind of regulation for creating a picture. The process of understanding then 
devises a similar image for the recipient, but one that is less clear. In addition to that, the recipient can put together the meanings of the individual terms from the context of the statement. The ability to understand sentences includes the ability to construct schemas - and thus possible realities. If thinking is the construction of reality or of "possibility«, then simply understanding sentences is an activity that is difficult to separate from thinking (Dörner 1998: 47).

In his work The Language and Thought of the Child (cf. Piaget 1926), developmental psychologist Jean Piaget postulated the close connection between the ability to speak and to think. The child's intellectual, cognitive and linguistic development is based on the haptic-sensual experience of the environment. Accordingly, strong language ability is an indication of higher cognitive skills. The cognitive abilities he observed in children of prespeaking age led him to conclude that thinking was independent of language.

\section{Context}

The context of this research is architectural education at the boundary between knowledge and ability. Designing is traditionally learned in studio work within a design project; here, methods and skills are imparted directly. A large part of the knowledge transfer consists of skills that cannot be formalized and is based on symbolic representations or sketches. Even many experts often fail to articulate which skills they have and how they use them.

Thus, the production of knowledge in architecture has little to do with practice because practicelargely consists of implicit knowledge (cf. Heylighen/ Martin/Cavallin 2006: 2); in this regard, tacit knowing, knowledge, and the knower form one entity. A comparison with the process of language acquisition is again worthwhile because this is also achieved through practice. Initially, individual expressions and rules are learned. The framework for using an idiom must first be internalized so that a virtuoso use of the language is possible. The artistic lingual expression in the sense of literature requires further involvement and skillfulness in dealing with language. This moment of »becoming literature « serves as a personal eye-opening moment when dealing with language. In architectural education, the search for this moment is often replaced with the search for a concept to illustrate a thought. With regard to knowledge transfer and communication, the discussions of situated cognition theorized by Jean Lave might be revealing. This notion concerns anchoring individual learning in context. 


\section{The Echo of Language in the Body}

Recent neuropsychological findings demonstrate the strong connection between language and the body. Studies have shown that the sensorimotor system is activated in connection with language, even if it points to abstract connections (Boulenger et al. 2009: 1910-1919).

According to the neurobiologist and linguist Boulenger, abstract meanings in the human brain are not only generated by activation of the fronto-temporal cortex, i.e. the semantic center, but also by complementary activations of the sensorimotor system, which add to it (Boulenger et al. 2009: 1912). "These results establish for the first time the differential involvement of motor and premotor cortex in idiom processing and support theories that view abstract semantics as grounded in action-perception systems « (Boulenger et. al. 2009: 1910).

\section{Knowledge of the Body}

The tactile experience of the world forms our prior knowledge related to the world. In the overlap of experience and our imagination, we can use and apply it:

»Our conception of a tree for example [...] arises by the tacit integration of countless experiences of different trees and pictures and reports of still others: deciduous and evergreen, straight and crooked, bare and leafy. All these encounters are included in forming the conception of a tree; they are all used subsidiarily with a bearing in the conception of a tree, which is what we mean by the word tree« (Polanyi 1969: 163).

Tacit knowledge is acquired through experience and practical action. Accordingly, it is also the result of failure and correction. It is comprehensively present in each person: »It is the skill of the hands, the knowledge of the skin, and of the deep layers of the brain« (Puusa/Eerikäinen 2010: 309).

Polanyi distinguishes tacit knowing from explicit knowledge. Explicit knowledge is characterized by the fact that it can be formalized and passed on, for instance in written form. Accordingly, it is independent of a knowing person (Heylighen/Martin/Cavallin 2005). Tacit knowledge can usually not be articulated, and it generally constitutes the necessary background knowledge to understand and handle the explicit knowledge. Furthermore, 
all knowledge is tacit knowledge or based on it (cf. Polanyi 1958; Polanyi 1966: 4). Therefore, it is not a separate form of knowledge, but an integral part of all knowledge.

The theory of the embodiment, which stems from recent cognitive science, describes the close integration of the body and mind when generating knowledge. Many aspects of cognitive processes depend heavily on the specific properties of a body, reaching beyond the cognition of the brain, in the interplay of perception - cognitive and motor skills (cf. Wilson/Foglia 2015). Thus only through the manifestation of the body in the world does knowledge become possible:

»Mind is embodied, meaning is embodied, and thought is embodied in this most profound sense. [...] According to such a view, there is no ultimate separation of mind and body, and we are always in touch with our world through our embodied acts and experiences« (Lakeoff / Johnson 2002: 249).

Under the influence of Merleau-Ponty and his explanations of the phenomenology of the body - the idea of overcoming the body as a mechanism-initself and consciousness as being-for-itself - sociologist Harold Garfinkel developed the theory of ethnomethodology. Garfinkel assumed that by observing the everyday and professional world, important actions and processes of knowledge generation could be examined. This school of thought later became known as "studies of work«. It examines the formal structures of practical processes. Textbook knowledge has a model character that cannot simply be transferred to everyday practical work. This gap between theory and practice, or between textbook and reality, exemplifies the everyday experience that can only be acquired through practical action in the social structure of the work context (Bergmann 2005: 132).

The knowledge of experience thus contains those contents of the human mind that arise while exercising the profession or in other contexts that enable people to act professionally. The »studies of work« explore this field of research in different occupations and work contexts. Even in (seemingly) context-independent activities such as performing a mathematical proof, it is shown how such an activity constitutes a craft in the interplay of blackboard, chalk, and hand.

A structure that contains knowledge, like a word or an action, is ambiguous in the sense that it can contain more than one state of knowledge depending on the context. Conversely, content can appear in various states 
or contexts. According to the ethnomethodological reading, common scientific language fails here. Rigid categorizations cannot reflect the rich, yet vague and ambiguous everyday language (cf. Garfinkel 1967).

\section{Conclusion}

With this text, I aim to further widen the broad field of questions concerning the specific knowledge contained in the design process. The phenomenon of language and implicit actions associated with tacit knowledge increase our awareness of the design process as a professional practice. A further step could entail generating new pedagogical frameworks for design education in architecture. Acknowledging and developing the specific knowledge impersonated in a designer is of great importance for the future of our profession. It concerns knowledge, which is hard to generalize, paraphrase, or formalize in an abstract process without the control of a person. Moreover, a discerning and educated personality who exercises the cycle of making acquiring - understanding and who is enabled to do so by their previously accumulated knowledge, is irreplaceable in the design process, especially in the increasingly automated processes of generative design. Furthermore, new potentials emerge to intervene in the design process and to develop new methods. From the researched phenomena, new tools can be derived that could be used for the design process.

Concluding, this text constitutes a plea for understanding through doing. We cannot deny this ability by the increasing mechanization of the design processes, as it takes an educated personality to classify and transfer the generated content into a broader context.

\section{References}

Bergmann, Jörg (2005):

»Ethnomethodologie«, in: Uwe Flick/

Ernst von Kardorff/Ines Steinke (eds.), Qualitative Forschung. Ein Handbuch, Reinbek bei Hamburg: Rowohlt.
Boulenger, Véronique/Hauk, Olaf/ Pulvermüller, Friedemann (2009): „Grasping Ideas with the Motor System: Semantic Somatotopy in Idiom Comprehension «, in: Cerebral Cortex, August 2009, 19(8), 1905-1914. doi: 10.1093/ cercor/bhn217 
Dörner, Dietrich (1998): »Sprache und Denken«, in: Mannheimer BeiträgeSonderheft 1998, http://www-1v75. rz.uni-mannheim.de/ Publikationen/ MA\%20Beitraege/Sh98/Sonderheft98. pdf $\#$ page $=41$, accessed September 18 , 2019.

Garfinkel, Harold (1967): Studies in Ethnomethodology, Englewood Cliffs, N]: Prentice Hall.

Heylighen, Ann/Martin, Mike W./Cavallin, Humberto (2005) »How to Teach and Archive Tacit Design Knowledge «, in: Design Intelligence 11(6).

Heylighen, Ann/Martin, Mike W./Cavallin, Humberto (2006): »Building Stories Revisited: Unlocking the Knowledge Capital of Architectural Practice «, in: Architectural Engineering and Design Management, Volume 3, 65-74.

Kleist, Heinrich von [1805]: Über die allmählige Verfertigung der Cedanken beim Reden. - English translation: On the Gradual Completion of Thoughts During Speech, transl. by John S. Taylor, Amsterdam/Berlin/ Stuttgart: edenspiekermann, [2006] 2011, https://spiekermann.com/en/wp-content/ uploads/2008/11/Kleist_speech_ende.pdf, accessed January 17, 2021.

Lakoff, George/Johnson, Mark (2002): »Why Cognitive Linguistics Requires Embodied Realism«, in: Cognitive Linguistics 13(3), 245-263. DOI: 10.1515/cogl.2002.016

Lutzeier, Peter (1985): Linguistische Semantik, Stuttgart: Metzler.

Merleau-Ponty, Maurice [1945]:

Phénoménologie de la perception. - English translation: Phenomenology of Perception [first transl. 1962 by Colin Smith], transl. by Donald Landes, Abingdon: Routledge, 2013.

Piaget, Jean [1923]: Le Langage et la pensée chez l'enfant. - English translation: The Language and Thought of the Child [1926], transl. by Marjorie and Ruth Gabain, New York/London: Routledge, 1959.
Polanyi, Michael (1958): Personal Knowledge: Toward a Post-Critical Philosophy, London: Routledge \& Kegan Paul.

Polanyi, Michael (1966): The Tacit Dimension, London: Routledge \& Kegan Paul.

Polanyi, Michael (1969): Marjorie Greene (ed.), Knowing and Being: Essays by Michael Polanyi, London: Routledge \& Kegan Paul.

Puusa, Anu/Eerikäinen, Mari (2010): »Is Tacit Knowledge Really Tacit?«, in: Electronic Journal of Knowledge Management, Vol. 8, Issue 3, 307-318.

Schwarz, Monika (2008): Einführung in die Kognitive Linguistik, Stuttgart: UTB.

Seiler, Thomas Bernhard (2012):

Evolution des Wissens, Band 1: Evolution der Erkenntnisstrukturen, Münster: LIT Verlag.

Sennett, Richard (2008): The Craftsman, New Haven: Yale University Press.

Wilson, Robert A./Foglia, Lucia (2015): »Embodied Cognition«, in: Edward N. Zalta (ed.), The Stanford Encyclopedia of Philosophy, https://stanford.library.sydney.edu.au/ entries/embodied-cognition, accessed January 17, 2021.

Wittgenstein, Ludwig [1953]: Philosophische Untersuchungen. - English translation: Philosophical Investigations [first transl. 1953 by G. E. M. Anscombe] rev. fourth edition, transl. by G. E. M. Anscombe, P. M. S. Hacker and Joachim Schulte, Hoboken, N]: Wiley-Blackwell, 2009. 
